\title{
English Teachers' Perception on the Use of Authentic Assessment in 2013 Curriculum
}

\author{
Moch. Said Mardjuki \\ Indonesia University of Education, Indonesia \\ e-mail: saidmardjuki@student.upi.edu
}

\begin{abstract}
:
Authentic assessment in 2013 Curriculum leads the students to be autonomous learner and become higher order thinking. However, the English teachers prefer to use non-authentic than authentic assessment. This study seeks to find out how English teachers use the authentic assessment in the classroom and the barriers and the way the English teachers solve the problems in conducting authentic assessment. Interview was used to find out of five postgraduate English education students at a university in Bandung used authentic assessment in the classroom. Authentic assessment can encourage the English teachers and students to be more creative and optimize student's participation in learning process. However, several challenges lead to the implementation of authentic assessment: purpose of assessment, fairness, time allotment, objectivity and reliability of scoring. Therefore, 2013 Curriculum should be clearly stated the types of authentic assessment, the indicators, and time allocation to its teaching material.
\end{abstract}

Keywords: Authentic Assessment, 2013 Curriculum, Teachers' Perception 


\section{Introduction}

Authentic assessment in Indonesia becomes one of the major concerns in 2013 curriculum as stated in The Regulation of the Minister of Culture and Education of the Republic of Indonesia Number 104 Year 2014 which promotes learner autonomy and critical thinking as a part of higher order thinking skills. In reality, most teachers still prefer the traditional assessment. It can be clearly seen in several summative test types where the teachers usually used multiple choice test than composing writing.

The aims of this study are to know the teachers' perception on the use of authentic assessment and the barriers in conducting authentic assessment in the classroom. Some theories related to authentic assessment were proposed by Ariev, 2005; Gulikers, Bastiaens, and Kirschner, 2004; Lombardi, 2008. They stated that authentic assessment deals with an assessment used by the teachers in order to meet the specific criterion which based on the same competencies, or combination of knowledge, skills, and attitudes. Thus, there are four criteria that will be used in the authentic assessment. The four criteria from Herrington and Herrington (2006, p. 147) are as follows: "(1) Context; (2) problem solving skills, higher order thinking and production of knowledge; (3) Task factor which stimulates a wide range of active responses; and (4) indicator which provides multiple indicators of learning, achieves validity and reliability". Moreover, O’Malley and Pierce (1996: 4) mention three types of authentic assessment they are performance assessment, portfolios, and students-self assessment.

Besides, the implementation of authentic assessment can facilitate students' diversity in learning and as well as appreciate the diversity of cultures (DuBabcock,2016). Moreover, it is also believed that the administration of appropriate testing can create supporting classroom learning environment (Arigusman, 2017). Then, the authentic assessment pinpoints the students to have critical thinking as it is shown in their productive assessment; speaking and writing. Martinez Lirola and Irwin (2016) claim that when the learners are able to understand the contextual constraints of a specific text type and its path to accomplishing its objective, they are able to write effectively. It is in line with the current curriculum objectives that by comprehending the text types, the students are able to communicate actively in the forms of spoken and as well as in the written form.

Fithriyani (2014) conducted a research seeking the challenges in the implementation of authentic assessment as what has been proposed in 2013 Curriculum. The findings indicate that utilizing this kind of assessment is quite challenging since condition of real class does not support. Further, managing time, putting fairness and purpose of the assessment, and teachers' objectivity are the major challenges that can cause problems in applying this assessment. Likewise, Hijriati (2014) conducted a research seeking the implication of authentic assessment to students' self-esteem. The findings indicated that the use of authentic assessment describe the competencies or knowledge which students have related to the teaching materials. Students feel worthy because of the application of authentic assessment in which the teachers either provide responsible judgement on students' progress or performance or constructive guidance along the teaching and learning process. Retnawati, Hadi, 
and Nugraha (2016) found that most of vocational high school teachers and vice principals of curriculum in Yogyakarta had difficulties in implementing assessment of 2013 curriculum. They had not fully understood about the assessment system. Moreover, Adeyemi (2015) conducted a research discusses the contribution of authentic and portfolio assessment to the teaching and learning process. It revealed that those type of tests would able to ensure the academic success of the students.

Reflecting to the previous elaboration, this study is aimed to find out how English teachers use the authentic assessment in the classroom and the barriers and the way the English teachers solve the problems in conducting authentic assessment. The underlying reason behind the study is few studies concerning investigations related to the use of authentic assessment in teaching learning process, particularly teaching English at senior or vocational high schools.

\section{Literature Review}

\subsection{Authentic Assessment}

Authentic assessment based on The Regulation of the Minister of Culture and Education of the Republic of Indonesia Number 104 Year 2014 is clearly defined as a form of assessment allowing students to elaborate behavior, knowledge, and skills gained from the learning process in accomplishing assignment in real situation or context. Besides, Retnawati, Hadi, Nugraha (2016) also defined authentic assessment as a process of measuring students' knowledge in comprehensively based on the criterion of the subjects which shown on the student's performances, motivation, as well as local wisdom included. Prendeville and Wellman (2011) in Hijriati (2014) defined authentic assessment as a kind of gathering information relates to the students' achievement in learning language in comprehensive ways based on the criterion of the curriculum. From those above definitions, it can be concluded that authentic assessment is a recent type of assessment used in Indonesian curriculum which is emphasized the teacher to measure the students' achievement based on the reflection and monitoring in the learning process.

Related to the implementation of 2013 curriculum, authentic assessment is strongly relevant since it can describe students' achievement as it is recommended in the new approach of 2013 curriculum; scientific approach. Thus, it is not only deal with students' achievement and motivation but it also kind of washback for teachers regarding the improvement in their teaching and learning process as well. Thus, the four language skills: listening, speaking, reading, and writing can be covered by using authentic assessment. Indeed, teachers may provide some possible specific objectives on their authentic assessment which relevant to their teaching in order to meet the students need that replicate real world performances as closely as possible. Therefore, it is more capable to provide information of students' ability holistically and validly. Moreover, Authentic assessment that used in the evaluation assess the students ${ }^{\text {ee }}$ readiness, process, and outcomes of learning as a whole. It is similar with the 2013 curriculum learning outcomes which emphasized that an assessment is able to cover attitude competencies (spiritual and social), knowledge, and skills (The 
Regulation of the Minister of Culture and Education of the Republic of Indonesia Number 104 Year 2014, 2014).

\subsection{Types and Functions of Authentic Assessment}

Based on The Regulation of the Minister of Culture and Education of the Republic of Indonesia Number 104 Year 2014, 2014 and Johnson (2002, p. 167). Types of authentic assessment include portfolio, project, performance, and extended written response.

Portfolio is seemingly quite possibly the most popular form of authentic assessment. An intrinsic part of ongoing class work, the portfolio arises from the context of daily life (Adeyemi, 2015). It is in written form in which teacher and students determine the topic and kind of work which is based on the instructional objectives including certain period of time they will conduct it (Marhaeni, 2003). During the process, teacher supervises and observes the student's progress to see if there is problem to be solved together as well as do some improvements. As they do various tasks, students appraise them and collect them, and in the process see themselves as creative and capable. As in the case of any authentic assessment task, objectives must be clear.

The Project, this kind of authentic assessment evaluates students' task in the forms investigation including the planning, data collecting, organizing, analysis, and presenting within a period of time (Johnson, 2002). This assessment is aimed to know the students' understanding in applying and informing to a certain subject. As its name, project assessment demands students to complete or create a project on specific topic individually or in a small group agree with the instructional objectives. After that, the projects done by the students are presented through oral or written reports. This may be effective if the students are taught to deliver a procedural presentation about project description.

In performance tasks, students demonstrate for an audience that they have mastered specific learning objectives (Johnson, 2002). Then, how to evaluate a performance task, the performance task shows that students have:

- Mastered the specific information, concepts, and skills contained in the learning objectives.

- Understood and met the criteria appropriate to the performance. A wooden model of an Elizabethan theater, a musical composition, and an oil painting each has its own criteria, for example.

- Show cased personal interests and talents.

- Communicated effectively with the audience.

- Provided a balanced narrative and/or follow-up discussion of the thinking behind the final performance.

Extended written responses enable students to display their command of learning objectives while cultivating higher order thinking skills. Written responses may occur in a wide range of formats including. For instance, the persuasive letter, 
technical training manual, brochure, feasibility study, research essay, and short essay (Johnson, 2002).

These broad categories, the possibilities for authentic assessment task are rich as one's imagination. The procedure for designing an authentic assessment task: first, describe exactly what students should know and be able to demonstrate. Let them know the standards to be met. Second, call for connecting study in a meaningful way with a real-world context, or call for simulating a real-world context that carries meaning. Third, require students to show what they can do with what they know, to display deep knowledge and skill, by producing a result for example, a tangible product, presentation, collection of work. Fourth, decide on the levels of proficiency to be met. Fifth, express these levels of proficiency in a rubric, that is, a scoring guide that provides criteria for judging the task. Sixth, familiarize students with the rubric. Engage students in on-going self-evaluation as they appraise the quality of their own work on this assessment. Seventh, involve an audience beyond the teacher to respond to the assessment (Johnson, 2002).

Whatever form authentic assessment might take-whether maintaining a portfolio, developing a project, giving a performance, or preparing an extend response question - it allows students to demonstrate the full range of their learning while simultaneously adding to their knowledge and skill (Johnson, 2002).

\subsection{The implementation of Authentic Assessment}

In order to implement the principles of authentic assessment in 2013 Curriculum that has been in effect in Indonesia, the government has set several regulations. The assessment in 2013 curriculum is regulated through The Regulation of the Minister of Culture and Education of the Republic of Indonesia Number 81 Year 2013 which has been revised into The Regulation of the Minister of Culture and Education of the Republic of Indonesia Number 104 Year 2014. The main point of both regulations is found on the authentic assessment. There are four competencies that will be measured in the authentic assessment and the four competencies are as follows: spiritual and social attitude, knowledge, and skill. Each of the competencies will be measured by means of different techniques.

Therefore, the implementation of authentic assessment should cover the domains in the objectives of education: cognitive, affective, and psychomotor as formulated by Bloom et. al (taxonomy). The instrument of assessment which prepared by the teacher must be in accordance with the characteristics and complexity of the material in the content standards and competency standards. Thus the instrument will provide accurate information about the level of achievement of the students' competence.

\section{Research Methodology}

It is a qualitative research aiming at exploring and understanding the issue (Hamied, 2017, p.195). It was chosen since this study tried to investigate how English teachers use the authentic assessment in the classroom and the barriers and the way the English teachers solve the problems in conducting authentic assessment in 
comprehensive ways which were still easily understood. The data collection procedures conducted in the study comprises participants involved in the study, instrumentation and materials, and procedures taken in collecting the data.

Five postgraduate second semester English education students were selected purposively to participate in the study. There were three males and two female students participated in the study. They were selected purposively by the assumption that they have rich information (Creswell, 2012, p. 206) related to authentic assessment. Thus, they are English teachers who have implemented authentic assessment at their schools. The participants teach at senior or vocational high schools in Indonesia which have implemented 2013 curriculum since 2014.

Research instrument is an instrument or facility used by researcher to ease the data collecting and get better result (Arikunto, 1997). The research instrument employed in the present study was interview. Interview seemed to be the best way in capturing how the English teacher use authentic assessment in the teaching and learning process. The research instrument is enclosed in the appendices. The data gained were analyzed qualitatively. It employed the data analysis technique proposed by Miles and Huberman (1994) who set the analysis through three procedures: data reduction, data display, and conclusion drawing/verification.

\section{Findings}

This section addresses the following questions: (1) how do English teachers use the authentic assessment in the classroom? And (2) what are the barriers and how do the English teachers solve them in conducting authentic assessment in the classroom? The interview questions 1,2 , and 3 provide general information of the participants. The interview questions $4,5,6$, and 7 address the first research question, while the interview questions 8,9 , and 10 address the second research question.

All the participants have implemented authentic assessment in their teaching and learning process. Since they have joined workshops or trainings regarding the implementation of 2013 Curriculum, some of them have known the authentic assessment since 2014 and 2015. The workshops or trainings were held by either schools or other parties related to the development of education in Indonesia: Education Office, Lembaga Penjamin Mutu Pendidikan (LPMP), Pusat Pengembangan dan Pemberdayaan Pendidik dan Tenaga Kependidikan (P4TK). Thus, relating to the workshops or training materials, it mainly discussed about the paradigm in 2013 curriculum; approaches, methods, evaluation and assessment. However, the evaluation and assessment has limited portion in the workshops or trainings. In line with the limitation of evaluation and assessment included in the trainings or workshops. Some of them felt the trainings were not appropriate enough since it used at the first grade, while, they taught at the second or the third grade which were used School-Based Curriculum (KTSP). Indeed, they less motivation in joining the trainings. In line with less motivation in joining 2013 Curriculum trainings, some of the participants need more implemented trainings which could cover the trainings materials into teaching and learning process included evaluation and assessment which has different focus and form of evaluation with School-Based 
Curriculum (KTSP) because there are a lot of aspects to be included and analyzed in assessment. Moreover, a participant need more trainings to make her more comprehending on 2013 Curriculum.

\subsection{The Use of Authentic Assessment}

Relating the use of authentic assessment in teaching and learning process. The participants were asked several questions leading them to explain their experience on using authentic assessment in their teaching and learning process. Firstly, the participants were asked regarding their background of knowledge dealt with the definition of authentic assessment. It was based on their understanding on it. They define the authentic assessment as:

T1: ... a kind of assessment which is used to know how far the students have already achieved relates to what a teacher taught...

T2: ... student progress", ... achievement day today week per week to evaluate students' progress.

T3: ... used by the teachers to evaluate the students regarding what the materials have been achieved by the students and it is not only to assess the materials in the classroom but also to assess peer assessment or evaluation of the students (student's characters in relation to the materials). it could be in the classroom or outside the classroom.

T4: ... deals with specific assessment use to describe about student's achievement on learning.

T5: ... a kind of holistic assessment conducted every day comprehensively which covers student's affective, cognitive, and psychomotor.

Secondly, the participants were asked about the way they knew about authentic assessment. Most participants knew authentic assessment from the trainings or workshops. The way they obtained the definition of authentic assessment can be seen to the following findings:

T1: ... from workshop held by the school or learnt from the internet and language teaching books as well.

T2: ... from the workshops held by the school.

T3: ... from workshop held by the education office at my district and also my school.

T4: ... from the workshops held by schools and other related institutions such as LPMP and Education office.

T5: ... from the workshops or trainings held by the schools or related institutions.

Thirdly, the participants were asked about types of authentic assessments that they usually use in conducting authentic assessment. It relates to the way they use of authentic assessment in the teaching and learning process. They stated that:

T1: To be honest, I have not applied it during my teaching process. I prefer to use the traditional one which is in the form of multiple choice test. 
T2: I have conducted it but inappropriate procedures. Since I am not familiar to use this kind of assessment.

T3: I usually use scoring rubric but I don't think that the rubric meets the requirement as it is needed on the curriculum. I make it by myself to help me in scoring.

T4: I usually use portfolio, project based, and performance-based

T5: I usually use peer-assessment, project based, portfolio, and performancebased.

The last interview questions deal with the first research question of how the participants conduct authentic assessment in the teaching and learning process. They usually:

T1: ... assess them from three aspects; academic (cognitive) such as giving them questions related to the text, affective, and psychomotor. If I test a dialogue, I usually using scoring rubric for psychomotor but not scoring rubric in assessing cognitive; I use non-authentic assessment or I use traditional way (multiple choice). Sometime I mix the authentic and nonauthentic assessment.

T2: ... follow the assessment format as given by school, in every daily exam, I just put the score based on the format given then it becomes average of each student since it calculates automatically.

T3: ... use portfolio to assess my student's homework, performance-based to speaking and as well as the use of scoring rubric.

T4: ... use portfolio to assess my student's homework, project based to assess my student's writing in certain kinds of texts, and performance-based to assess my student's speaking and reading performance. Then, in assessing my student's ability, performance, and attitude, I usually use scoring rubric based on certain criterion.

T5: ... use peer-assessment to assess my student's attitude which is assessed by their friends, project based is used to assess particularly dealing with student's ability in writing, portfolio is used to assess my student's homework, and performance-based is used to assess my student's speaking ability. Since I teach at SMK, I usually use performance-based.

Based on the findings above we can see that all the participants have adequate background of knowledge related to the use of authentic assessment in the teaching and learning process. They gathered the information through seminars, trainings, and reading either from teaching books or relevant sources from internet.

\subsection{The Barriers and Solutions}

The changing curriculum leads several changing into the curriculum elements: approach, methods, evaluation and assessment. Relating conducting authentic assessment at schools the participants found several challenging in using it onto their teaching and learning process. Indeed, the participants also make the solution to solve the barriers. The challenging and solutions of this findings address the second research question. Most participants found relatively same challenging in conducting 
authentic assessment. on the other hand, only a participants have not found any barriers related the use of authentic assessment. Those challenges are clearly seen in the following:

T1: There are two most difficult parts in using authentic assessment, particularly in assessing student's speaking and writing: analyzing and time consuming. The first is when I have to analyze each component in the rubric. Such as in assessing speaking, I have to analyze the components in one time while the student is presenting or performing. Thus, I have to avoid subjectivity relating scoring. The second is time consuming. Since I have to assess and give scoring to each students which based on each criterion.

T2: The first is time consuming. It is the most common barriers I found. Since, I have to count and then recount the student's score. Then, I have to make criterion for each items (scoring rubric) and it covers to all the students. The second one is the total number of students in a class which is also effected to the implementation of the appropriate authentic assessment.

T3: There would no barriers to conduct authentic assessment since we have managed our teaching time to suit with the assessment.

T4: There are two mains difficulties in conducting authentic assessment. Those are time consuming and the students number in a class. It takes time in conducting authentic assessment since we have to assess each student in comprehensively and assess them based on the criterion stated in scoring rubric.

T5: There are three barriers I found in conducting authentic assessment. those are time consuming, the number of the students in a class, and student's lack of capability to submit the assignment punctually. To measure each student ability or performance based on the criterion provide in scoring rubric is time consuming. Since we have to give scoring for each criterion and analyze it. Then, we have to describe their achievement either in the form of scoring or words. The second is the total number of the students in a class is also determine the effectiveness of authentic assessment in class. The last is the teachers have to ask the students to submit the tasks before the due date.

There are several problems faced by the participants: time-consuming, lack of motivation of the students in submitting the tasks, teacher's subjectivity in scoring, and the total number of the students in a class.

In order to solve the barriers faced by the participants. There are several ways conducted by the participants to solve the barriers. It can be seen in the following response:

T1: I usually make my rubric simpler, there is no criterion to be used. It is only the whole score based on my observation: 70,80 , or 90 . It makes me easier in scoring.

T2: I make such as time prediction (my total time in teaching) to make equality in scoring to each student. So, I am able to cover all the students in term of scoring. Thus, I have to be aware about the total number includes in the 
testing. if it is short, I will do it in authentic assessment. whereas it consists lots of items or numbers to be tested, I usually used non-authentic assessment.

T3: ...

T4: I usually make a folder for each class. It consists of teaching journal and scoring rubric (I adapted from relevant sources) in order to help me to conduct authentic assessment. Thus, I tend to give more rewards for the lower-level students, so, the affective assessment is prioritized.

T5: I usually use a kind of journal in which cover the students affective, cognitive, and psychomotor. I also ask help from other English teachers at my school related to the use of authentic assessment. for example, in deciding criterion of scoring rubric, topic of project writing as well as their presentation. Then, I usually use authentic assessment on mid-term test which make them more prepared.

The participants usually use a kind of folder to keep the student's works and as well as journal. Thus, they usually make teaching plan particularly related to the use of assessment, it could be related to schedule and types of testing is going to be used.

\section{Discussion}

Dealing with the definition of authentic assessment, most of the participants define authentic assessment as a kind of assessment to measure student's achievement, progress, and as a holistic assessment which covers cognitive, affective, and psychomotor. The participants' definition regarding authentic assessment was relevant with the definition of authentic assessment proposed by Fitriyani (2014). She defined authentic assessment as an assessment method done by the teachers which aims at describing students' achievement and needs in the teaching learning process through reflection and monitoring.

Regarding the way how they got the information related to definition of authentic assessment, most of the participants obtained the information from trainings, workshops, internet, and teaching books. However, they got limited information related to the definition about authentic assessment and its implementation in the teaching and learning process. It is relevant to the study conducted by Retnawati, Hadi, and Nugraha (2016) finding that most teachers and vice principals in Yogyakarta found difficulties in using authentic assessment since they had limited information about it, even they had joined trainings or workshops related to the use of assessment in 2013 Curriculum.

Moreover, portfolio is commonly used as one of the types of authentic assessment in the teaching learning process since it deals with seeking student's progress in certain period of time. It is relevant to the study conducted by Adeyemi (2015) and Marhaeni (2003). They found that portfolio became one of the major types of authentic assessment to be used by the teachers. Whereas, most of the participants were not have sufficient knowledge regarding to construct the scoring rubric. They are used to making it by themselves without any revision. It is relevant with the study conducted by Retnawati, Hadi, and Nugraha (2016) finding that most of 
teachers of vocational high schools in Yogyakarta found difficulties to develop the instrument of an authentic assessment as well as to design scoring rubric for the skills, and to gather the scores from multiple measurement techniques.

The teachers' difficulties were also found in: developing the instrument of attitude, implementing the authentic assessment, formulating the indicators, designing the assessment rubric for the skills, and gathering the scores from multiple measurement techniques. In addition, the teachers could not find feasible application for describing the students' learning achievement.

Related to the barriers found during the use of authentic assessment in the teaching and learning process, most participants agreed that there were three kinds of barriers. They are fairness, time-consuming, and teacher's objectivity. These barriers usually happen and affect the implementation in the teaching process. Besides, the total number of students and the lack motivation of students in submitting the tasks became other contributing factors. Those problems were relevant to the study conducted by Fithriyani (2014). She found that there were four challenges in conducting authentic assessment, such as: managing time, putting fairness and purpose of the assessment, and teachers' objectivity. Thus, in order to solve the barriers, most participants used schedule which is based on the teaching objectives. It based on the materials covered in the syllabus. If it had lots of materials to be tested, they would like to use non-authentic test and if it was not, they would like to use authentic assessment. It is in line with The Regulation of the Minister of Culture and Education of the Republic of Indonesia Number 104 Year 2014 which stated that there are two kinds of assessment to be used: authentic and non-authentic assessment. In line with the Regulation, Fithriyani (2014) suggested four steps in solving the challenges in conducting authentic assessment. First, teachers have to define the purpose of the assessment related to the instructional objectives in order to bring consistent combination on the extent to those purposes. Second, Teachers have to lead students to learn how to express critical thinking towards the problem given in the assignment. Third, teachers have to manage time-allotment well if they want to implement this assessment. The last, teachers have to use inter-rater reliability to ensure consistency and fairness.

\section{Conclusion}

The use of authentic assessment in 2013 Curriculum bring its beneficial since it allows the English teachers and students to be more creative and motivated in the teaching and learning process. Indeed, this kind of assessment also leads several challenges which are effected to the its implementation into the teaching and learning process. The challenges are purpose of assessment, fairness, time allotment, as well as objectivity and reliability of scoring. Therefore, the English teachers should be well-prepared in order to overcome those challenges before implementing authentic assessment.

Based on the findings of this study, the government should provide trainings and workshops relate to the implementation of the authentic assessment in the learning process which is based on the objectives as it stated on the syllabus as well as the 
indicators, therefore, it can be included in the scoring rubric in order to meet the objectivity of authentic assessment used in the teaching and learning process. Thus, the time allotment of each type of authentic assessment should be clearly stated in order to make authentic assessment work properly.

\section{References}

Adeyemi, B. A. (2015). The efficacy of authentic assessment and portfolio assessment in the learning of social studies in junior secondary schools in Osun State , Nigeria. Ife PsychologIA, 23(2), 125-132.

Ariev, P.R. (2005). A theoretical model for the authentic assessment of teaching. Practical Assessment, Research \& Evaluation, 10(2), 1-11.

Arigusman, Anggi. (2017). Indonesian EFL Learners' Perceptions of Classroom Learning Environments in An EFL Context. ASIAN TEFL, 2(2), 2017

Arikunto, Suharsimi. (2002). Prosedur Penelitian: Suatu Pendekatan Praktek. Jakarta: Rineka Cipta.

Creswell, John W. (2012). Educational Research: Planning, Conducting, and Evaluating Qualitative and Quantitative Research. Boston: Pearson.

Du-Babcock, Bertha. (2016). Assessing the Effects of Short-Term Culture and Language Immersion Program: A Hong Kong Case. ASIAN TEFL, 1(2), 2016

Fithriyani. (2014). Implementing Authentic Assessment: A Challenge for English Language Teachers. In Proceedings of the $61^{\text {st }}$ TEFLIN International Conference, 7-9 October 2014 (pp. 1151-1154). Solo: Sebelas Maret University.

Gulikers, J. T. M., Bastiaens, Th. J., \& Kirschner, P. A. (2006). Authentic assessment, student and teacher perceptions: the practical value of the five dimensional-framework. Journal of Vocational Education and Training, 58, 337-357

Hamied, F. A. (2017). Research Method: A Guide for First-Time Researchers $\left(2^{\text {nd }}\right.$ edition). Bandung: UPI PRESS.

Herrington, J. \& Herrington, A. (2006) Authentic conditions for authentic assessment: Aligning task and assessment, in Critical Visions, Proceedings of the 29th HERDSA Annual Conference, Western Australia 10-12 July 2006, 146-151. Retrieved from http://ro.uow.edu.au/cgi/viewcontent.cgi?article=2164\&context=edupapers.

Hijriati, Hanifatul. (2014). Authentic Assessment and the Implications to Students' Self Esteem in Teaching English at Senior High School. In Proceedings of the 61 ${ }^{\text {st }}$ TEFLIN International Conference, 7-9 October 2014 (pp. 1155-1158). Solo: Sebelas Maret University. 
Johnson, Elaine B. (2002). Contextual Teaching and Learning. USA: Corwin Press, Inc.

Lombardi, M.M. (2008). Making the grade: the role of assessment in authentic learning. Retrieved from http://www.net.eduhouse.org.

Marhaeni, A. A. I. N. (2003). Portfolio Assessment in a Competence-based English as a Foreign Language (EFL) Instruction. Jurnal Pendidikan dan Pengajaran IKIP Negeri Singaraja, Edisi Khusus TH. XXXVI Desember 2003. ISSN 0215-8250.

Martinez Lirola, Maria and Irwin, Derek S. (2016). Challenges in the Application of Genre Theory to Improve L2 Academic Writing: Effective Reports and Assessment. ASIAN TEFL, 1(1), 2016. DOI: http://dx.doi.org/10.21462/asiantefl.v1i1.4

Miles, Mathew B. And Huberman, A. Michael. (1994). Qualitative Data Analysis. USA: Sage Publications.

O’Malley, J.M., and Pierce, L. Valdez. (1996). Authentic Assessment for English Language Learners: Practical Approaches for Teachers. New York: AddisonWesley Publishing Company.

Retnawati, H., Hadi, S., \& Chandra Nugraha, A. M. (2016). Vocational High School Teachers' Difficulties in Implementing the Assessment in 2013 curriculum in Yogyakarta Province of Indonesia. International Journal of Instruction, 9(1), 1694-609. https://doi.org/10.12973/iji.2016.914a

The Regulation of the Minister of Culture and Education of the Republic of Indonesia Number 104 Year 2014. 